\title{
EFEITO DO NITRATO E AMÔNIO SOBRE O CRESCIMENTO E EFICIÊNCIA DE UTILIZAÇÃO DO NITROGÊNIO EM MANDIOCA ${ }^{(1)}$
}

\author{
JAILSON LOPES CRUZ $\left({ }^{*}\right)$; CLAUDINÉIA REGINA PELACANI $\left({ }^{3}\right)$; WAGNER LUIZ ARAÚJO $\left({ }^{4}\right)$
}

\begin{abstract}
RESUMO
Desenvolveu-se o presente estudo visando-se avaliar o efeito da fonte nitrogenada sobre o acúmulo de matéria seca e a absorção, distribuição e utilização de nitrogênio em mandioca. Para a instalação do experimento utilizou-se a variedade Cigana preta, cultivada em solução nutritiva e em vasos com capacidade para $11,0 \mathrm{~L}$. O nível de nitrogênio na solução foi de $12 \mathrm{~mol} \mathrm{~m}^{-3}$ e os tratamentos consistiram de cinco proporções de $\mathrm{NO}_{3}{ }^{-}: \mathrm{NH}_{4}{ }^{+}$, conforme segue: 12:0, 9:3, 6:6, 3:9 e $0: 12 \mathrm{~mol} \mathrm{~m}^{-3}$. No encerramento do experimento, que ocorreu 90 dias após o plantio, verificou-se que as menores quantidades de massa seca total foram obtidas para as plantas cultivadas tendo apenas nitrato ou amônio como fonte de nitrogênio. Nesse aspecto, o amônio foi mais prejudicial ao crescimento do que a fonte nítrica. A concentração de $\mathrm{NH}_{4}{ }^{+}$livre no tecido vegetal foi maior para as raízes de absorção, seguida pelas folhas e raízes de armazenamento. A eficiência de absorção de nitrogênio foi maior para as plantas cultivadas sob as maiores proporções de $\mathrm{NH}_{4}{ }^{+}$. Os resultados evidenciaram que a cultura da mandioca cresce melhor quando ocorrer na solução de crescimento uma mistura de $\mathrm{NO}_{3}{ }^{-}$e $\mathrm{NH}_{4}{ }^{+}$, principalmente nas proporções de 9:3 e 6:6 mol m${ }^{-3}$.
\end{abstract}

Palavras-chaves: massa seca, área foliar, raízes de armazenamento, relação raiz:parte aérea, eficiência no uso de nitrogênio.

\section{ABSTRACT \\ EFFECT OF NITRATE AND AMMONIUM ON GROWTH AND EFFICIENCY OF NITROGEN USE BY CASSAVA PLANTS}

This study was carried out to evaluate the effect of nitrogen source on dry mass accumulation and absorption, distribution and also use of nitrogen by cassava plants. Cigana Preta cultivar plants were grown in nutrient solutions set up in $11.0 \mathrm{~L}$ containers. Nitrogen concentration in solutions was $12 \mathrm{~mol}$ $\mathrm{m}^{-3}$. Treatments included five combinations of $\mathrm{NO}_{3}^{-}: \mathrm{NH}_{4}{ }^{+}$, that is, 12:0, 9:3, 6:6, 3:9 and 0:12 $\mathrm{mol} \mathrm{m}^{-3}$. Aftert 90 days the dry mass was determined. The lowest total dry mass values were obtained for plants grown with just nitrate or ammonium as nitrogen source. In this sence, ammonium affected growth more than the nitric source. The concentration of free $\mathrm{NH}_{4}{ }^{+}$was higher for absorption in roots, followed by leaves and storage roots. The efficiency of nitrogen absorption was higher for plants cultivated under highest proportions of $\mathrm{NH}_{4}{ }^{+}$. The results showed that cassava plants grow more when growth solution contains a mixture of $\mathrm{NO}_{3}{ }^{-}$and $\mathrm{NH}_{4}{ }^{+}$, especially at the proportions of 9:3 and $6: 6 \mathrm{~mol} \mathrm{~m}^{-3}$.

Key words: dry matter, leaf area, storage root, root:leaf ratio, nitrogen use efficiency.

$\left({ }^{1}\right)$ Recebido para publicação em 15 de junho de 2005 e aceito em 1. ${ }^{\circ}$ de junho de 2006.

$\left({ }^{2}\right)$ Embrapa Mandioca e Fruticultura Tropical, Caixa Postal 007, 44380-000 Cruz das Almas (BA). E-mail jailson@cnpmf.embrapa.br. *Autor correspondente.

$\left({ }^{3}\right)$ Universidade Estadual de Feira de Santana, Departamento de Biologia Vegetal, Rod. BR-116, 44031-460 Feira de Santana (BA).

$\left({ }^{4}\right)$ Estudante de Pós graduação, Departamento de Biologia Vegetal, Universidade Federal de Viçosa, 36571-000 Viçosa (MG). 


\section{INTRODUÇÃO}

O nitrogênio (N) participa da formação de diversos compostos considerados de suma importância para o crescimento e desenvolvimento das plantas, destacando-se as proteínas e as clorofilas. Assim, plantas cultivadas sob deficiência de $\mathrm{N}$ podem não expressar seu potencial produtivo, visto que sob tais condições podem ocorrer reduções significativas na taxa de formação e expansão foliar e na taxa assimilatória líquida por unidade de área. No caso de mandioca, a deficiência pode ser ainda mais prejudicial visto que esse nutriente é extremamente importante para a formação e o crescimento das raízes de reserva (CRUZ et al., 2004a), dois dos principais determinantes da produtividade da cultura. Além da quantidade de nitrogênio disponível, um fator que pode alterar o crescimento das plantas é a proporção nitrato $x$ amônio $\left(\mathrm{NO}_{3}^{-}: \mathrm{NH}_{4}{ }^{+}\right.$) presente no solo (BARKER e MiLls, 1980).

$\mathrm{O} N$ pode ser encontrado, principalmente, nas formas de nitrato e amônio na solução do solo; porém, na maioria dos solos cultivados, em particular na zona tropical, o nitrato é a principal forma de aquisição de N pelas plantas (MARSCHNER, 1995). Nas condições em que haja inibição da nitrificação e, ou, o nitrato esteja em processo de intensa lixiviação, ao contrário do amônio que é retido com mais facilidade pelas partículas do solo, é possível constatar ambas as formas presentes na solução do solo (HUBER et al., 1977; Gasser, 1961; Fredeen e Field, 1992). Adicionalmente, a utilização das técnicas de fertirrigação pode disponibilizar tanto o $\mathrm{N}$ na forma de nitrato quanto na forma de amônio em curtos intervalos de tempo, reduzindo, assim, a transformação do nitrogênio pelos microrganismos do solo. Em revisão realizada por Lemos (1996) atesta-se que as taxas de absorção relativas de nitrato e amônio pelas plantas superiores são influenciadas por fatores como: a proporção de $\mathrm{NO}_{3}{ }^{-}: \mathrm{NH}_{4}{ }^{+}$no meio, $\mathrm{pH}$, temperatura, intensidade luminosa, concentração de carboidratos nas raízes, entre outros. Além disso, algumas espécies tendem a absorver o nitrato mais rapidamente do que o amônio, enquanto outras agem justamente ao contrário, preferindo absorver o amônio. Em adição à absorção diferencial, o uso do nitrogênio absorvido também pode variar em função da proporção de $\mathrm{NO}_{3}{ }^{-}: \mathrm{NH}_{4}{ }^{+}$no meio de cultivo, pois, o nitrato para ser utilizado necessita ser reduzido, em um processo dependente de energia e mediado pelas enzimas redutase do nitrato e redutase do nitrito, enquanto o amônio dispensa essa etapa para ser assimilado (TAiz e ZeIger, 1998). Apesar dessa alta demanda energética para a utilização do nitrato, o crescimento das plantas é melhor quando supridas com nitrato e não com amônio (BARKER e Mills, 1980). Essa aparente contradição tem determinado o aprofundamento das pesquisas visando identificar os motivos pelos quais as plantas cultivadas, em sua maioria, tem o crescimento reduzido quando na solução do solo existe apenas o íon amônio. Uma possibilidade é que a necessidade de desintoxicação da planta, em função do excesso de amônio absorvido, pode anular essa vantagem em termos de custo energético (GIVAN, 1979; RAAB e TERrY, 1995; Guo et al., 2002).

Em adição à influência sobre o crescimento, a relação $\mathrm{NO}_{3}^{-}: \mathrm{NH}_{4}{ }^{+}$também pode provocar alterações no modelo de distribuição da massa seca acumulada. Resultados observados por Lewis et al. (1989) evidenciaram que as raízes das plantas de trigo foram mais sensíveis ao amônio do que a parte aérea, resultando em significativa redução da relação raiz:parte aérea; no entanto, em milho não foi observada nenhuma alteração dessa natureza.

Assim, o objetivo deste trabalho foi avaliar o crescimento e a absorção, distribuição e utilização de $\mathrm{N}$ pela mandioca, quando cultivada sob diferentes proporções de nitrato e amônio no meio de cultivo.

\section{MATERIAL E MÉTODOS}

O experimento foi desenvolvido em casa de vegetação do Departamento de Biologia Vegetal da Universidade Federal de Viçosa. A cultivar Cigana Preta (Manihot esculenta Crantz, BGM 116) foi escolhida para o experimento. Essa variedade tem bom potencial produtivo, sendo indicada pelo Centro Nacional de Pesquisa em Mandioca e Fruticultura Tropical (CNPMF/EMBRAPA) para plantios comerciais em algumas áreas da Região Nordeste do Brasil.

Para o plantio utilizaram-se manivas de aproximadamente $0,15 \mathrm{~m}$ de comprimento. O substrato utilizado foi areia grossa de rio, lavada várias vezes com água de torneira e, por último, com água destilada para a retirada da matéria orgânica, argilas e minerais. Os vasos tinham capacidade de 11,0 L. Inicialmente, foram plantadas duas manivas em cada vaso. Nos primeiros 10 dias, os vasos foram irrigados, duas vezes ao dia, com água de torneira. Após esse período, foi descartada a planta menos vigorosa e o experimento passou a ser desenvolvido com apenas uma planta por vaso. Em seguida ao desbaste, o substrato passou a ser fertilizado com soluções nutritivas, modificadas a partir da solução utilizada por CRUZ (2001). Esse autor indicou $12 \mathrm{~mol} \mathrm{~m}^{-3} \mathrm{de} \mathrm{NO}_{3}{ }^{-}$ como a concentração que proporcionou os melhores crescimentos das plantas de mandioca dessa mesma cultivar. Com base nesse valor foram preparadas 
soluções com cinco proporções de $\mathrm{NO}_{3}{ }^{-}: \mathrm{NH}_{4}{ }^{+}$, em mol $\mathrm{m}^{-3}:(12: 0 ; 9: 3 ; 6: 6 ; 3: 9$ e $0: 12)$. Diariamente era realizada a reposição da água evapotranspirada, com água destilada. Semanalmente, os vasos eram lavados com água de torneira e água destilada, para evitar a salinização do substrato, e a solução renovada seguindo o mesmo método descrito por CRUZ (2001). Por esse método, cada tratamento recebia, por semana, 3,4 L de solução. Noventa dias após o início do experimento, foram retiradas amostras, de aproximadamente $0,5 \mathrm{~g}$, da lâmina foliar da última folha totalmente expandida e das raízes de absorção e de armazenamento para a determinação do $\mathrm{NH}_{4}{ }^{+}$. A extração foi realizada com etanol $80 \%$ fervente. Em seguida, o extrato foi despigmentado, evaporado até a secura, em evaporador rotativo a vácuo, a $45{ }^{\circ} \mathrm{C}$ e ressuspendido em água destilada (CRUZ, 2001). Do extrato final, tomaram-se alíquotas para a determinação colorimétrica do $\mathrm{NH}_{4}{ }^{+}$livre, conforme método descrito por WEATHEBURN (1967).

Posteriormente, todas as folhas foram destacadas da planta, contadas e a área foliar medida com um integrador de área marca Delta T, mod. MK2. As raízes de armazenamento, classificadas por TANKOU et al. (1990) com diâmetro maior do que $0,5 \mathrm{~cm}$, foram destacadas e contadas. Em seguida, as folhas, pecíolos, caule, raízes de absorção e raízes de armazenamento foram colocadas, separadamente, para secar a $75{ }^{\circ} \mathrm{C}$, em estufa com circulação de ar forçada. Após 96 horas, foi medida a massa seca dessas diferentes partes da planta.

O material vegetal seco foi moído em moinho tipo Willy e padronizado com peneira de 20 mesh. Aproximadamente em $0,1 \mathrm{~g}$ da massa seca dos diferentes órgãos da planta houve digestão sulfúrica e a concentração de $\mathrm{N}$ total determinada colorimetricamente utilizando-se o reagente de Nessler (Umbreit et al., 1972). Com os dados de massa seca e a concentração de $\mathrm{N}$ foram calculados os seguintes parâmetros: (a) Conteúdo total de $\mathrm{N}$ - somatório da massa seca de cada órgão multiplicada pela concentração de N; (b) Eficiência na absorção de N conteúdo total de $\mathrm{N}$ dividido pela massa seca das raízes de absorção; (c) Eficiência no transporte de $\mathrm{N}$ - conteúdo de $\mathrm{N}$ da parte aérea dividido pelo conteúdo total de $\mathrm{N}$; e (d) Eficiência no uso de $\mathrm{N}$ (massa seca total) ${ }^{2}$ dividida pelo conteúdo total de $\mathrm{N}$ do tecido vegetal (SIDDIQI e GLASS, 1981).

O delineamento experimental utilizado foi o de blocos ao acaso, com sete repetições para os dados de crescimento e cinco repetições para a concentração de $\mathrm{NH}_{4}^{+}$livre e $\mathrm{N}$ total. Cada parcela experimental foi constituída por uma planta. Para efeito de comparação entre os tratamentos, calculou-se, para cada média, seu respectivo erro-padrão.

\section{RESULTADOS E DISCUSSÃO}

Durante o período experimental não foi observado sintoma de toxidez característico das plantas sensíveis ao íon amônio. Dos órgãos avaliados, verificou-se que a concentração de $\mathrm{NH}_{4}{ }^{+}$ livre foi maior nas raízes de absorção, seguida pelas folhas e raízes de armazenamento (Figuras 1A, 1B e 1C). A retenção de parte significativa do amônio absorvido nas raízes é relacionada à sua capacidade de suportar maiores concentrações desse íon do que as folhas (BARKER e Mills, 1980).
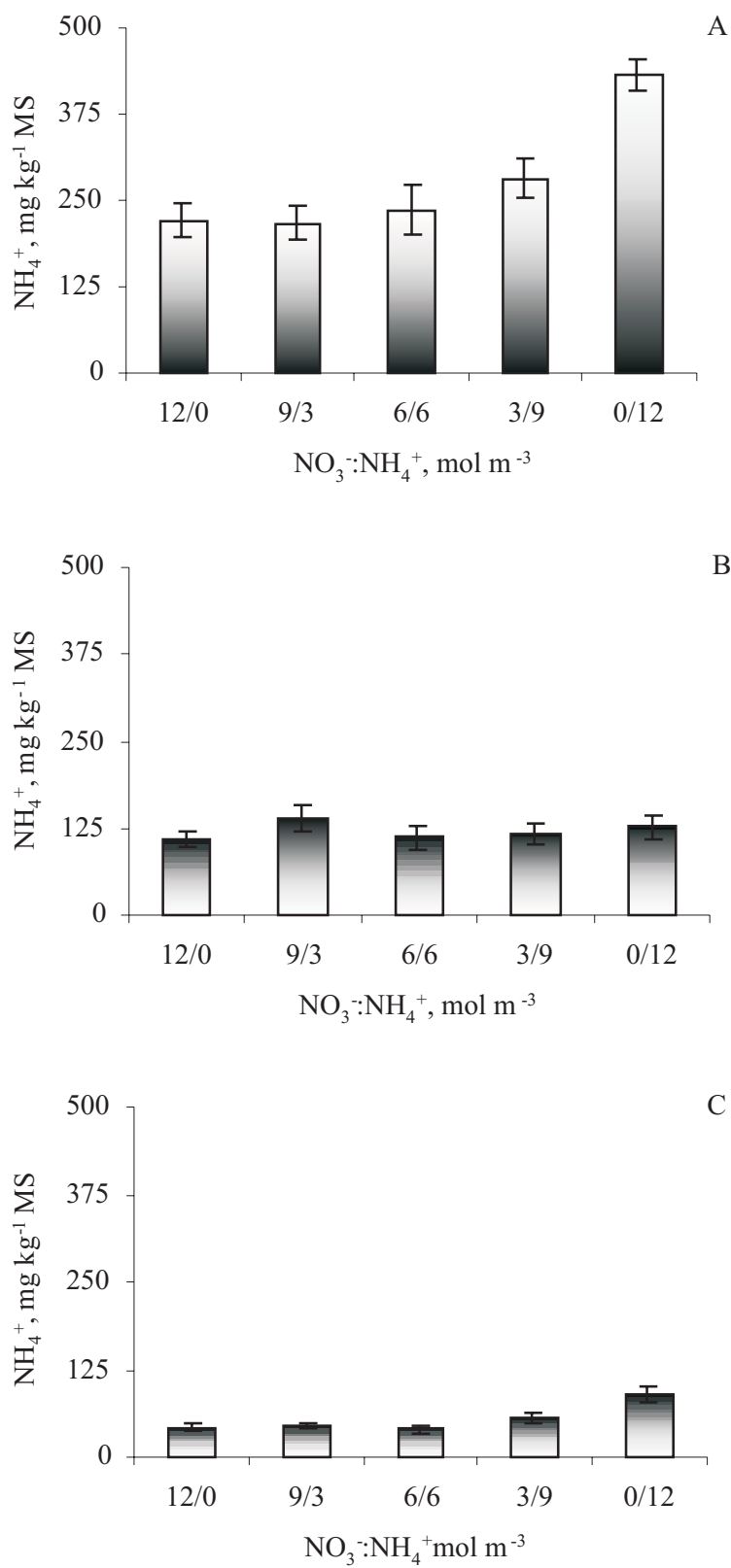

Figura 1. Efeito da relação $\mathrm{NO}_{3}{ }^{-}: \mathrm{NH}_{4}{ }^{+}$sobre concentração de $\mathrm{NH}_{4}{ }^{+}$livre nas raízes de absorção (A), folhas (B) e raízes de armazenamento $(C)$ em plantas de mandioca cultivadas em solução nutritiva por 90 dias. 
Nas folhas, as concentrações de amônio não variaram significativamente em função dos tratamentos aplicados. Para as raízes de absorção, apenas o tratamento em que se utilizou a concentração mais alta de amônio diferiu dos demais. Esses resultados sugerem boa capacidade das plantas de mandioca em assimilar rapidamente parte do amônio absorvido, evitando-se o acúmulo desse íon em concentrações tóxicas, o que é suportado pelas observações realizadas por CRUz et al. (2004b) que, em mandioca, o aumento na disponibilidade interna de amônio pode aumentar a atividade das enzimas do sistema GS-GOGAT-GDH, responsáveis pela assimilação desse íon.

Os teores de amônio das raízes de armazenamento, principalmente dos tratamentos em que se utilizaram as duas maiores concentrações de amônio, parecem comprovar que essa parte da planta pode ser utilizada como destino de parte do excesso de amônio absorvido, também contribuindo para amenizar os possíveis efeitos tóxicos desse íon sobre outros órgãos da planta.

As maiores quantidades de massa seca total foram obtidas com plantas cultivadas nas proporções de 9:3 e 6:6 $\mathrm{mol} \mathrm{m}^{-3}$ de $\mathrm{NO}_{3}^{-}: \mathrm{NH}_{4}{ }^{+}$(Figura 2A). Já as menores, foram obtidas quando se usou apenas nitrato ou amônio como fonte de N. Ainda, o amônio como única fonte proporcionou menores acúmulos de massa seca do que a fonte nítrica suprida sozinha. Menores acúmulos de matéria seca, quando algumas plantas são cultivadas apenas com nitrato ou amônio na solução de crescimento, também têm sido observados para cultivares de feijão (GuAZELLI, 1988), milho (SCHRADER et al., 1972) e tomate (GANMORE-NeUmANn e KAFKAFI, 1980). A redução no acúmulo de biomassa está relacionada, entre outros fatores, ao maior custo energético para a absorção do nitrato (FERNANDEs e Rossielo, 1986). A estimativa é que a redução e assimilação do nitrato possam consumir até $25 \%$ dos processos associados à fotossíntese e ao transporte de elétrons que ocorre em nível de mitocôndrias (BLOOM et al., 1989). No caso do amônio, esse íon pode concorrer para a redução da fotossíntese líquida (GOYAL et al., 1982); redução na absorção de alguns macronutrientes, notadamente potássio, cálcio e magnésio (GuAZzelLI, 1988); alteração nos balanços osmótico e hormonal das plantas (GERENDÁs et al., 1997), redução do pH da solução do solo (MARSCHNER, 1995) e aumento na resistência ao fluxo de água, que pode induzir situações de estresse hídrico (ADLER et al., 1996).

Observa-se nas figuras $2 \mathrm{~B}$ e $2 \mathrm{C}$ que os tratamentos constituídos exclusivamente de nitrato ou amônio também proporcionaram menor número de folhas, e as folhas formadas ficaram menores. Esses resultados, tomados em conjunto, explicam os menores valores de massa seca da folhas obtidos por esses tratamentos (Figura 2D). Em comparação com o tratamento 9:3 mol m${ }^{-3}$ de $\mathrm{NO}_{3}{ }^{-}: \mathrm{NH}_{4}{ }^{+}$, nas plantas supridas apenas com nitrato, verificou-se redução de aproximadamente $10 \%$ no número de folhas e de $15 \%$ na área foliar; já o amônio proporcionou reduções de $21 \%$ e $31 \%$, respectivamente. Esses resultados atestam que o $\mathrm{NO}_{3}{ }^{-}$e, mais efetivamente, $\mathrm{o} \mathrm{NH}_{4}{ }^{+}$foram mais prejudiciais à expansão do que ao aparecimento das folhas, em semelhança ao que foi observado por RAAB e TERRY (1994). Esse efeito do amônio sobre a expansão foliar tem sido relacionado à alteração negativa provocada no potencial hídrico foliar em função da maior resistência hidráulica das raízes (ADLER et al., 1996), à menor translocação de citocininas das raízes para a parte aérea (WALCH-LiU et al., 2000) e à menor absorção de cátions (RAAB e TERRY, 1995).

Em plantas supridas com 9:3 e 6:6 $\mathrm{mol} \mathrm{m}^{-3}$ de $\mathrm{NO}_{3}{ }^{-}: \mathrm{NH}_{4}{ }^{+}$, observaram-se valores de massa seca do sistema radicular de absorção em torno de 13,9 g, enquanto nas plantas supridas apenas com nitrato ou amônio houve produções de 10,9 g e 7,23 g respectivamente (Figura 2E). A redução na massa seca das folhas proporcionada pelo amônio, em comparação ao nitrato, foi de $12 \%$, enquanto para o sistema radicular de absorção essa redução foi de 33\%. A maior redução do sistema radicular das plantas cultivadas exclusivamente com amônio determinou redução da relação raiz:parte aérea dessas plantas (Figura 2F). Esse processo tem sido atribuído ao fato de que os carboidratos translocados das folhas para as raízes de absorção são utilizados, prioritariamente, como esqueletos de carbono e energia para o processo de assimilação desse íon, visando evitar seu acúmulo em níveis tóxicos, e não para os processos associados ao crescimento desse órgão (Lewis et al., 1989).

A massa seca do caule e pecíolo seguiu o mesmo padrão verificado para as folhas e raízes de absorção (Figura 3A e 3B). Observou-se que o número de raízes de armazenamento foi maior para as plantas cultivadas nas proporções 3:9; 6:6; e 9:3 $\mathrm{mol} \mathrm{m}^{-3}$ de $\mathrm{NO}_{3}{ }^{-}: \mathrm{NH}_{4}{ }^{+}$(Figura 3C). Tanto o amônio quanto o nitrato, quando utilizado como única fonte de $\mathrm{N}$, reduziram em mais de $30 \%$ a formação dessas raízes. Também, a massa seca das raízes de armazenamento foi maior para os tratamentos em que se usou a combinação de nitrato e amônio na solução nutritiva (Figura 3D). Porém, quando se compara o nitrato com o amônio, como únicas fontes de $\mathrm{N}$, verifica-se que o amônio determinou maior número e maior acúmulo 
de massa seca nas raízes de armazenamento. Os maiores valores da relação raiz de armazenamento:massa seca total (Figura 3E) foram obtidos quando o amônio esteve em maior proporção (exceção ao tratamento 9:3 $\mathrm{mol} \mathrm{m}^{-3}$ de $\mathrm{NO}_{3}^{-}: \mathrm{NH}_{4}^{+}$) evidenciando que o amônio reduz o fluxo de assimilados que pode ser utilizado para o crescimento de raízes de absorção, mas tende a aumentar o fluxo em direção ao crescimento e acúmulo de massa seca das raízes de armazenamento.
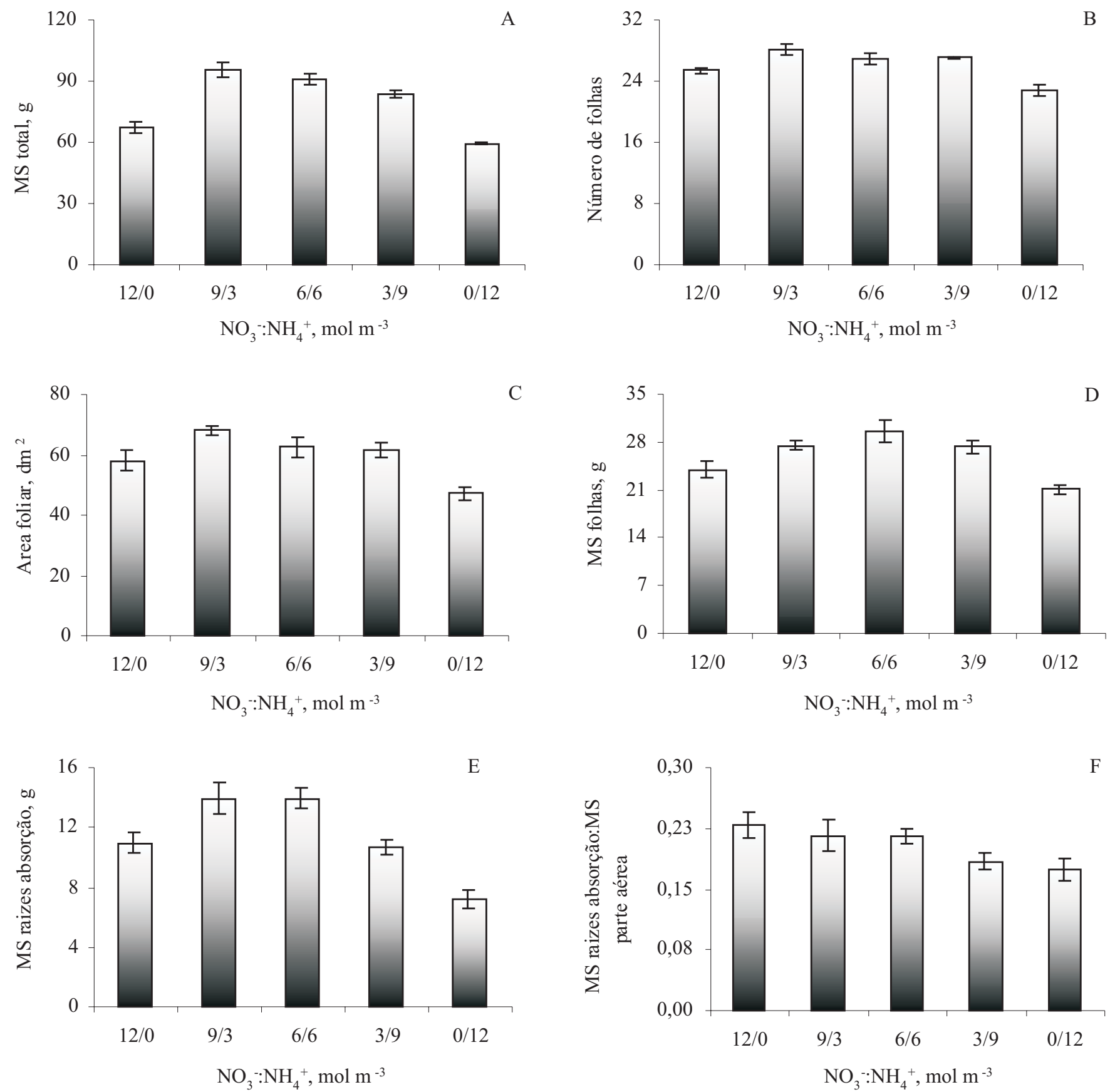

Figura 2. Efeito da relação $\mathrm{NO}_{3}{ }^{-}: \mathrm{NH}_{4}{ }^{+}$sobre a massa seca total (A), número de folhas (B), área foliar (C), MS folhas (D), MS raízes absorção (E) e relação raízes absorção:parte aérea (F) em plantas de mandioca cultivadas em solução nutritiva por 90 dias. 

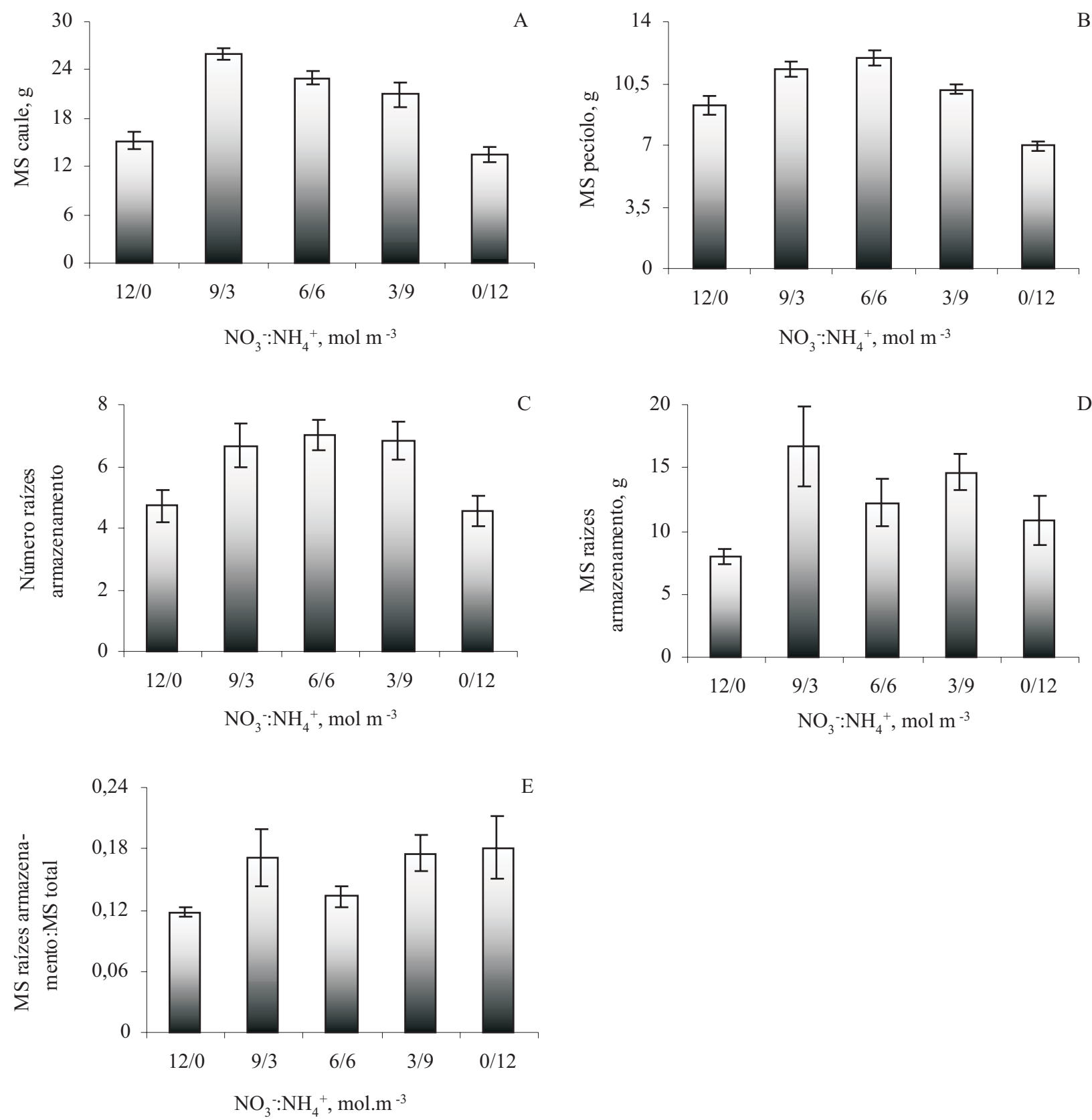

Figura 3. Efeito da relação $\mathrm{NO}_{3}{ }^{-}: \mathrm{NH}_{4}{ }^{+}$sobre a massa seca do caule (A), massa seca do pecíolo (B), número (C) e massa seca das raízes de armazenamento (D) e relação massa seca das raízes de armazenamento e massa seca total (E) em plantas de mandioca cultivadas em solução nutritiva por 90 dias.

Independentemente dos tratamentos utilizados, verificou-se que a concentração de $\mathrm{N}$, ao contrário da concentração de amônio, foi maior para as folhas, seguida das raízes de absorção e caule (Figura 4A). Nas folhas, as plantas cultivadas sob as maiores proporções de amônio $\left(0: 12\right.$ e $3: 9 \mathrm{~mol} \mathrm{~m}^{-3}$ de $\mathrm{NO}_{3}{ }^{-}: \mathrm{NH}_{4}{ }^{+}$) foram as que tiveram as maiores concentrações de N. À exceção do tratamento 12:0 mol $\mathrm{m}^{-3}$ de $\mathrm{NO}_{3}^{-}: \mathrm{NH}_{4}{ }^{+}$, essa mesma tendência foi observada para a raiz de absorção, caule e raízes de armazenamento. A menor concentração de $\mathrm{N}$ foliar, de $52 \mathrm{~g} \mathrm{~kg}^{-1} \mathrm{MS}$, foi obtida pelo tratamento em que se utilizou o nitrato como única fonte nitrogenada. Para Asher et al. (1980), a concentração de $\mathrm{N}$ foliar considerada normal em mandioca situa-se entre 50 e $60 \mathrm{~g} \mathrm{~kg}^{-1} \mathrm{MS}$; assim, é possível concluir que, mesmo para o tratamento $12: 0 \mathrm{~mol} \mathrm{~m}^{-3}$ de $\mathrm{NO}_{3}{ }^{-}: \mathrm{NH}_{4}{ }^{+}$, não houve limitação de $\mathrm{N}$ que pudesse justificar o menor crescimento das plantas. As altas concentrações de $\mathrm{N}$ observadas nos tratamentos em que se utilizaram as 
duas maiores concentrações de amônio parecem ressaltar que houve absorção de $\mathrm{N}$ além da capacidade de utilização nos processos de crescimento da planta. De modo geral, as menores concentrações de $\mathrm{N}$ foliar observadas nas plantas cultivadas com 9:3 e 6:6 mol m${ }^{-3}$ de $\mathrm{NO}_{3}^{-}: \mathrm{NH}_{4}{ }^{+}$ provavelmente estejam relacionadas aos maiores acúmulos de massa seca experimentado por essas plantas, um efeito denominado diluição. O conteúdo total de nitrogênio foi menor para as plantas cultivadas com soluções tendo apenas $\mathrm{NO}_{3}{ }^{-}$ou $\mathrm{NH}_{4}{ }^{+}$ como única fonte de $\mathrm{N}$, também como conseqüência do menor crescimento experimentado pelas plantas desses tratamentos (Figura 4B).
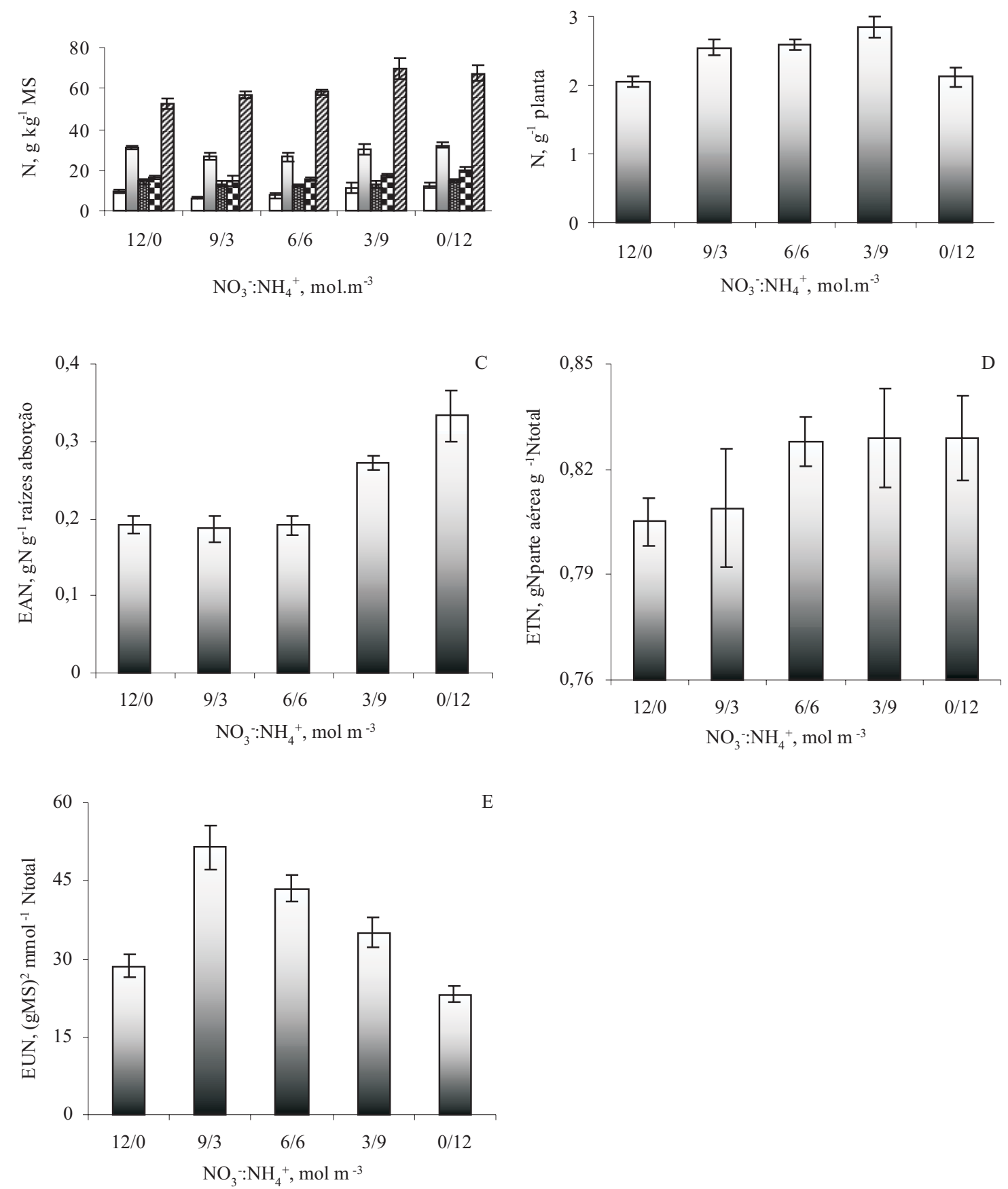

Figura 4. Efeito da relação $\mathrm{NO}_{3}^{-}: \mathrm{NH}_{4}{ }^{+}$sobre a concentração (A), conteúdo (B), eficiência de absorção (C), eficiência no transporte (D) e eficiência no uso de nitrogênio (E) em plantas de mandioca cultivadas em solução nutritiva por 90 dias. 
A eficiência de absorção de $\mathrm{N}$ (EAN) foi maior para os tratamentos que receberam as duas maiores proporções de $\mathrm{NH}_{4}{ }^{+}$(Figura $4 \mathrm{C}$ ). Ainda, a EAN das plantas que receberam apenas $\mathrm{NH}_{4}{ }^{+}(0,192)$ foi $70 \%$ superior à eficiência obtida pelas plantas que receberam apenas o $\mathrm{NO}_{3}{ }^{-}$. Esse resultado era esperado visto que FERNANDES e RosSiELo (1986) certificam que a absorção de $\mathrm{NO}_{3}{ }^{-}$ocorre contra um gradiente de potencial eletroquímico, enquanto a absorção do $\mathrm{NH}_{4}{ }^{+}$ é mais facilitada por ser menos dependente de energia. Essa maior eficiência de absorção, explicam as maiores concentrações de $\mathrm{N}$ obtidas pelas plantas cultivadas com altas proporções de amônio. Como mencionado, a alta eficiência na absorção pode ter determinado a necessidade no desvio de esqueletos de carbono e gasto energético para evitar-se o acúmulo excessivo de amônio e ter contribuído para o menor crescimento das plantas. Claramente, a eficiência no transporte de $\mathrm{N}$ (ETN) da raiz para a parte aérea foi menor para o tratamento em que se utilizou apenas o $\mathrm{NO}_{3}{ }^{-}$como única fonte de $\mathrm{N}$. Para os outros tratamentos, não houve diferença significativa, apesar de o tratamento 9:3 mol m${ }^{-3}$ de $\mathrm{NO}_{3}{ }^{-}: \mathrm{NH}_{4}{ }^{+}$tender a ser menor do que os tratamentos em que o $\mathrm{NH}_{4}{ }^{+}$estava presente em maior proporção (Figura 4D). Os menores valores no uso eficiente de $\mathrm{N}$ (UEN) foram verificados nos tratamentos 0:12 e 12:0 mol m${ }^{-3}$ de $\mathrm{NO}_{3}{ }^{-}: \mathrm{NH}_{4}{ }^{+}$ (Figura 4E). Para os demais tratamentos, o UEN foi reduzido à medida que se aumentava a participação do amônio no meio de crescimento. Esse menor UEN das plantas cultivadas com grandes proporções de amônio deveu-se ao menor crescimento, aliada à alta concentração de $\mathrm{N}$ em seus tecidos.

\section{CONCLUSÕES}

Nas plantas de mandioca quando cultivada tendo apenas o $\mathrm{NO}_{3}{ }^{-}$ou $\mathrm{NH}_{4}{ }^{+}$como única fonte nitrogenada, observaram-se os menores valores de massa seca total, sendo o $\mathrm{NH}_{4}{ }^{+}$mais prejudicial do que o $\mathrm{NO}_{3}{ }^{-}$. Nesse aspecto, a cultura da mandioca crescerá melhor quando ocorre, no meio de cultivo, uma mistura das duas fontes nitrogenadas, principalmente nas proporções de 9:3 e 6:6 mol m${ }^{-3}$ de $\mathrm{NO}_{3}^{-}: \mathrm{NH}_{4}{ }^{+}$.

\section{REFERÊNCIAS}

ADLER, P.R.; WILCOX, G.E.; MARKHART, A.H. Ammonium decreases muskmelon root system hydraulic conductivity. Journal of Plant Nutrition, New York, v.19, p.1395-1403, 1996

ASHER, C.J.; EDWARDS, D.G.; HOWELLER, R.H. Desórdenes nutricionales de la yuca (Manihot esculenta Crantz). Cali, Colombia: Centro Internacional de Agricultura Tropical, CIAT. 1980. 48p.
BARKER, A.V.; MILLS, H.A. Ammonium and nitrate nutrition of horticultural crops. Horticultural Review, Westport, v.2, p.395-423, 1980.

BLOOM, A.J.; CALDWELL, R.M.; FINAZZO, J.; WARNER, R.L.; WEISSBART, J. Oxygen and carbon dioxide fluxes from barley shoots dependent on nitrate assimilation. Plant Physiology, Bethesda, v. 191, p.352-356, 1989.

CRUZ, J.L. Efeitos de níveis de nitrato sobre o metabolismo do nitrogênio, assimilação do CO2 e Fluorescência da Clorofila $a$ em Mandioca. 2001. 87p. Dissertação (Doutorado) - Universidade Federal de Viçosa, Viçosa.

CRUZ, J.L.; PELACANI, C.R.; ARAÚJO, W.L. Relações biométricas de mandioca cultivada com variada disponibilidade de nitrogênio. Revista Científica Rural, Bagé, v.9, p.131-140, 2004a.

CRUZ,J.L.;MOSQUIM, P.R.;PELACANI, C.R.;ARAÚJO, W.L.;DA MATTA, F.M. Effects of nitrate nutrition on nitrogen metabolism in cassava. Biologia Plantarum, Prague, v.8, p.67-72, 2004b.

FERNANDES, M.S.; ROSSIELLO, R.O.P. Aspecto do metabolismo e utilização do nitrogênio em gramíneas. In: SIMPÓSIO SOBRECALAGEME ADUBAÇÃODE PASTAGENS, 1, Nova Odessa, 1985. Anais...Piracicaba, Associação Brasileira para Pesquisa da Potassa e do Fosfato, 1986. p. 92-123.

FREDEEN, A.L.; FIELD, C.B. Ammonium and nitrate uptake in gap: generalist and understory species of the genus Piper. Oecology, v.92, p.207-214, 1992.

GANMORE-NEUMANN, R.; KAFKAFI, U. Root temperature and percentage $\mathrm{NO}_{3}^{-} / \mathrm{NH}_{4}{ }^{+}$effects on tomato development. 1 . Morphopoly and growth. Agronomy Journal, Madison, v.72, p.758-761, 1980.

GASSER, J.K.R. Transformation, leaching and uptake of fertilizer nitrogen applied in autun and sprig to winter wheat on a heavy soil. Journal of the Science Food Agriculture, London, v.12, p.375-380, 1961.

GERENDÁS, J.; ZHU, Z.; BENDIXEN, R.; RATCLIFFE, R.G.; SATTELMACHER B Physiological and biochemical processes related to ammonium toxicity in higher plants. Zeitschrift für Pflanzenernährung und Bodenkunde, Weinheim, v.160, p.239-251, 1997.

GIVAN, C.V. Metabolic detoxification of ammonia in tissues of higher plants. Phytochemistry, Elmsford, v.18, p.375-382, 1979.

GOYAL, S.S.; LENZ, O.A.; HUFFAKER, R.C. Inhibitory effects of ammoniacal nitrogen on growth radish plants. I. Chracterization of toxics of $\mathrm{NH}_{4}^{+}$on growth and its alleviation by $\mathrm{NO}_{3}^{-}$. Journal of the American Society for Horticultural Science, Mount Vernon, v.107, p.125-129, 1982.

GUAZZELLI, E.M.F.M. Efeitos do nitrato e amônio no crescimento, assimilação e eficiência de utilização de nitrogênio por cultivares de feijoeiro (Phaseolus vulgaris L.) na fase inicial do crescimento. 1988. 112p. Dissertação (Mestrado) - Universidade Federal de Lavras, Lavras. 
GUO, S.; BRÜCK, H.; SATTELMACHER, B. Effects of supplied nitrogen form on growth and water uptake of French bean (Phaseolus vulgaris L.) plants. Plant Soil, Dordrecht, v. 239, p.267-275, 2002.

HUBER, D.M.; WARREN, H.L.; NELSON, D.W.; TSAI, C.V. Nitrification inhibitors: New tool for food production. BioScience, Washington, v.27, p.523-529, 1977.

LEMOS, G.B. de Crescimento e atividade das enzimas de assimilação do nitrogênio em plantas jovens de seringueira (Hevea brasiliensis Muell. Arg.) cultivadas com diferentes relações de nitrato e amônio. Lavras:UFLA. 1996. 56p. Dissertação (Mestrado) - Universidade Federal de Lavras, Lavras.

LEWIS, O.A.M.; LEIDI, E.O.; LIPS, S. H. Effect of nitrogen source on growth response to salinity stress in maize and wheat. New Phytologyst, Oxford, v.111, p.55-160, 1989.

MARSCHNER, H. Mineral Nutrition of Higher Plants. London: Academic Press, 1995. 889p.

RAAB, T.K.; TERRY, N. Nitrogen-source regulation of growth and photosynthesis in Beta vulgaris L. Plant Physiology, Bethesda, v.105, p.1159-1166, 1994.

RAAB, T.K.; TERRY, N. Carbon, nitrogen and nutrient interactions in Beta vulgaris L. as influenced by nitrogen source, $\mathrm{NO}_{3}$ ? versus $\mathrm{NH}_{4}^{+}$. Plant Physiology, Bethesda, v.107, p.575$584,1995$.
SCHRADER, L.E.; DOMSKA, D.; JUNG, J.R., P.E.; PETTERSON, L.A. Uptake and assimilation of ammonium-N and nitrate-N and them influence on the growth of corn (Zea mays, L.). Plant Physiology, Bethesda, v.64, p.690-695, 1972.

SIDDIQI, M.Y.; GLASS A.D.M. Utilization index: A modified approach to the estimation and comparison of nutrient utilization efficiency in plants. Journal of Plant Nutrition, New York, v.4, p.289-302, 1981.

TAIZ, L.; ZEIGER E. Plant Physiology. Massachusetts: Sinauer, 1998. 197p.

TANKOU, C.M; SCHAFFER, B.; O’HAIR, S.K.; SANCHEZ, C. A. Nitrogen shading duration, gas exchange and growth of cassava. HortScience, Alenxandria, v.25, p.1293-1296, 1990.

UMBREIT, W.W.; BURRIS, R.H.; STAUFFER, J.F. Manometric and biochemical techniques, $5^{\mathrm{a}}$ ed. Minneapolis, Burgess, Minnesota: 1972. 387p

WALCH-LIU, P.; NEUMANN, G.; BANGERTH, F.; ENGELS, C. Rapid effects of nitrogen form on leaf morphogenesis in tobacco. Journal of Experimental Botany, London, v.51, p.227$237,2000$.

WEATHEBURN, M.W. Phenol hipochloride reaction for determination of ammonia. Analytical Chemistry, Washington, v.39, p.971-974, 1967. 